\title{
Health beliefs and prescription medication compliance among diagnosed hypertension clinic attenders in a rural South African hospital
}

\author{
K Peltzer, Human Sciences Research Council, University of the North
}

\section{Abstract}

This study examines the relationship between health beliefs and the use of both prescribed medication and alternative healing agents among at least one year diagnosed hypertensives attending an hypertension out-patient clinic in a rural South African hospital. The sample included 33 men and 67 women, in the age range of 31 to 81 years, $(\mathrm{M}=60.7$ years, $\mathrm{SD}=9.8$ years). Main outcome measures included causative beliefs, health beliefs, and quality of the health care provider patient interaction. From the 100 patients studied $35 \%$ were not compliant with prescription medication. Most patients (almost $80 \%$ ) had taken something else for their high blood pressure apart from prescription medication, especially those who had been non-compliant with prescription medication. Most popular were the use of home remedies and faith healing, followed by traditional healing and over-the-counter drugs.

Non-compliant behaviour was associated with the use of alternative healing agents, the belief of curability of hypertension by traditional and faith healers, perceived benefits and barriers of antihypertensive medication and some items of the quality of the practitioner-patient relationship such as not explaining medical problems. Results are discussed in view of improving culturally sensitive compliance behaviour among hypertensive patients.

\section{Introduction}

The South African Demographic and Health Survey (DHS) (Department of Health, 1998: 32) showed that among persons above 15 years $11 \%$ of men and $13 \%$ of women were found to either have a blood pressure above $16(0 / 95 \mathrm{mmHg}$ or were taking appropriate medication to lower their blood pressure. A calculation based on these prevalence rates from the DHS and the census figures published for the South African population 15 years and older (Statistics South Africa, 1998: 5) leads to an estimate of about 3.3 million hypertensive people in the country. Overall, fewer hypertensive men $(9 \%)$ than women $(23 \%)$ are aware of their condition. Similarly, fewer hypertensive men in nonurban areas know that they suffer from the condition than their urban countreparts. This highlights that non-urban hypertensive males are the group with the most undiagnosed hypertension in the country and that they should be targeted to improve the diagnosis rate. This poor level of diagnoses in men is reflected in the low rates of men $(11 \%$ compared to $28 \%$ of women) who take appropriate drugs for hypertension. Consequently, only $9 \%$ of all men with hypertension had controlled blood pressure (BP<160/95 $\mathrm{mmHg}$ ), compared to $23 \%$ of hypertensive women. This is still a very low level of control and highlights the need to improve hypertension control in the country if premature death and disability are to be prevented. A more disturbing finding is that the control of hypertension in young patients is far worse than that achieved in older hypertensive patients. These are the hypertensive patients who require good control even more than older patients to prevent end organ damage while they are still part of the labour force of the country. For men, the worst level of control was reported in the African group, while for women it was found in non-urban African women (Department of Health, 1998: 32).

Patient drug use behaviours and compliance have been the focus of much research over the years. WHO (1993: 15f.) states that $50 \%$ of newly diagnosed patients with hypertension fail to make a referral appointment and as many as $50 \%$ of patients seeking treatment drop out of care within a year. Nyazema (1984: 552) found in Zimbabwe that hypertensive or diabetic patients had not complied with followup appointments since over $60 \%$ lacked comprehension of their disease and the use of the medicine prescribed to them. Esunge (1991: 293) identified the following factors in rural Cameroon that appeared to affect hypertensive patient compliance: free medication, free hospital visits, free transportation, open discussion with medical staff, use of a common dialect, and politeness of medical staff. Haynes 
McKibbon, Kanani, Brouwers and Oliver (1998: 3f.) reviewed that although adherence and treatment outcomes can be improved by certain, usually complex interventions, full benefits of medications cannot be realised at currently achievable levels of adherence. It is time that additional efforts be directed towards developing and testing innovative approaches to assist patients to follow treatment prescriptions. Morrel, Park, Kidder Morrel, and Martin (1997: 609) state that medication adherence is governed by both beliefs and cognitive factors. Therefore, measures of health behaviours, attitudes about health and medication taking, and cognitive function need to be recorded.

Among Jamaican women with hypertension it was found that the variables -perceived susceptibility, perceived severity and 'cue to action' - identified in the Health Belief Model need to be strengthened if patient compliance and adoption of health promoting behaviours are to be realized (Grant, 1993: 159). Anthropological research in clinical contexts has shown that differences between patient/practitioner models of health and illness can be the source of many problems in complying with treatment and that the patient's view of his or her own illness is important in the choices of treatment and therefore compliance (e.g. HeurtinRoberts \& Reisin, 1992: 787). Compliance studies generally have not investigated the role of alternative medicines in patients' treatment decisions. People's beliefs about and evaluations of health and medical care practices affect their choices among alternative actions. Since hypertension affects a large proportion of the black South African population, it is important to learn how health beliefs and perceptions affect the use of both formal and informal treatment practices.

A theoretical framework that has been used extensively in predicting preventive health behaviours is the Health $\mathrm{Be}$ lief Model (HBM) (Becker, 1979: 52). The model proposes that individual beliefs about severity and susceptibility of a disease and its consequences are associated with engaging in treatment action. Subjective assessments of disease threat are assumed to provide individuals with the motivating force to take action. Once an individual feels substantially threatened by a disease and its sequelae, he or she must decide among alternate actions. According to the $\mathrm{HBM}$, it is at this point that individuals perform a type of cost/benefit analysis such that alternatives are subjectively evaluated in terms of their benefits and costs (or barriers). This cost/benefit analysis then results in a preferred course of action or, in this research, a preferred health behaviour (Brown \& Segal, 1996: 904).

The purpose of this research was to examine the relationships between the health beliefs variables (health belief model, causative beliefs), quality of the health care patient relationship and drug use behaviour, i.e. compliance with prescribed antihypertensive medication, use of home remedies, traditional and faith healing.

\section{Methods}

\section{Sample and procedure}

The sample included 33 men and 67 women, in the age range of 31 to 81 years, $(M=60.7$ years, $S D=9.8$ years). The mean years of formal education was 7.5 years $(\mathrm{SD}=4.8$ years). Most (89) came from the village and some (11) were from an urban area. Fifty-nine were married or lived with a partner and 41 were single/separated/divorced/widowed. Almost all (97) belonged to the ethic group of Northern Sotho and three to Tsonga. The major religious denomination was Apostolic and Zion Christian Church (41), followed by Protestant type and Roman Catholic Churches (36), traditional or African religion (15), and other (9). Fourty-two rated themselves as quite well-off, 40 as not very well-off, 17 as quite poor, and one indicated to be wealthy.

Permission was obtained from the University of the North Ethics Committee and the Limpopo Provincial Health and Welfare Department. Patients diagnosed with hypertension for at least one year and consecutively attending an hypertension out-patient clinic until a sample of 100 was reached were included in the study. Before consultation the hypertensive patient was asked for formal consent to participate in the study. Thereafter an interview was conducted and a questionnaire was face-to-face administered with the patient by a trained research assistant. The questionnaires were translated and back translated by bilingual experts in the major language (Northern Sotho) used in the study. The schedule was field tested before the survey and modified by including traditional and faith healing of hypertension as potential barriers/costs and benefits. The questionnaire was pilot tested at time 1 on five hypertensive patients and after 4 weeks re-administered to the same patients. The responses from the first and second interview were comparable, and this is an indication of the reliability of the interview schedule.

\section{Measures}

1 Three items on previous health-seeking behaviour (answered by "yes" or "no"). (Internal consistency expressed with the Cronbach alpha coefficient for this sample was .65)

2 Four items on the curability of health care agents (rated from $1=$ agree to $3=$ disagree). (Cronbach alpha for this sample was .64)

3 Two questions assessing the patients" perceptions of high blood pressure with respect to its identity, or signs or symptoms used to tell when blood pressure is elevated ("Do you think you can tell when your blood pressure is up?"“ "How can you tell") (Meyer, Leventhal \& Gutmann, 1985: 120).

4 The Problem Portrait Technique on causative beliefs of hypertension (see Table 3) (MacLachlan, 1997: 84-9).

5 Health Beliefs: Questions developed by Brown and Segal (1996: 907ff.) for the four perception elements of the Health Belief Model (HBM) were measured on a 5-point Likert-type scale anchored by 1 ,,Strongly Agree" and 5 ,Strongly Disagree“ with 1 representing the strongest belief on each dimension.

The four components of the HBM are as follows:

- $\quad$ Perceived severity of hypertension (4 items) was measured in terms of the seriousness of hypertension, the fear of having hypertension and the limitation that hypertension imposes on 
social activities. (Cronbach alpha for this sample was .72)

- $\quad$ Perceived susceptibilty to consequences of hypertension ( 2 items). Perceived susceptibility is the degree to which an individual perceives her/himself to be vulnerable to consequences of uncontrolled hypertension. Perceived susceptibility was measured by the extent to which individuals believed it is probable that they would experience a stroke, heart attack or kidney problems and by their estimate of how much at risk they were to having a stroke, heart attack or kidney problems. (Cronbach alpha for this sample was .74)

- $\quad$ Perceived benefits of antihypertensive medication (3 items). Perceived benefits of antihypertensive medication $(\mathrm{Rx})$ represented the degree to which respondents believed their medication to be effective in controlling high blood pressure and preventing adverse consequences. Perceived benefits of $\mathrm{Rx}$ were measured in terms of the medication's ability to control high blood pressure, to prevent strokes, heart attacks and kidney disease, and to ease one's mind about having high blood pressure. (Cronbach alpha for this sample was .82)

- $\quad$ Perceived costs of hypertensive medication (4 items). Perceived costs of Rx were measured in terms of paying for the medication (financial), forgetting to take the medication, problem obtaining refills and experiencing side effects from the medication. (Cronbach alpha for this sample was .68)

- $\quad$ Perceived benefits of home remedies (HR)/traditional healing (TH)/faith healing ( $\mathrm{FH})$ ( 2 items for each treatment mode respectively) were measured by beliefs about home remedies'/traditional healing'/ faith healing' effectiveness in controlling high blood pressure and by their ability to keep the body and blood balanced. (Cronbach alpha for this sample was .73)

- $\quad$ Perceived costs of home remedies (HR)/traditional healing ( $\mathrm{TH}) /$ faith healing $(\mathrm{FH})$ (3 items for each treatment mode respectively) were measured in terms of the lack of physicians' acceptance of using HR/ $\mathrm{TH} / \mathrm{FH}$, the lack of comfort with discussing HR/TH/ FH use with their physicians, and the lack of efficacy of HR's/TH's/FH's compared to prescription medication. (Cronbach alpha for this sample was . 67)

6 A 20-item health carer satisfaction questionnaire (see Table 5)(Blumhagen, 1982: 323) (rated from $1=$ strongly agree to $6=$ strongly disagree). (Cronbach alpha for this sample was .69)

7 Sociodemographic data (8 items) and self-reported medication compliance.

\section{Data analysis}

Data analysis included descriptive, Chi-square, student ttest and discriminant statistics using the Staistical Package for the Social Sciences for Windows (SPSS-PC, version 10).

\section{Results}

Fourty-seven patients indicated that they had been diagnosed with hypertension in 1998, 46 in 1997, five in 1999 and 2 in 1996. The study was conducted from March to June 2000. Fourty-six rated their illness with very severe, 35 with not severe, and 18 with severe.

From the 100 diagnosed hypertensive patients 65 were found to be compliant and 35 non-compliant with prescription medication at their hypertension clinic visit. Compliance was defined as self-reported intake of medication for 30 times and non-compliance 29 times and less during the last month (Brown \& Segal, 1996: 908).

Table 1 indicates the health-seeking behaviour since first diagnosis with hypertension.

Most patients (almost 80\%) had taken something else for their high blood pressure apart from prescription medica-

\section{Table 1: Help-seeking behaviour for hypertensives other than biomedical since first diagnosis}

\begin{tabular}{|l|l|l|c|}
\hline Help-seeking for hypertension & $\begin{array}{l}\text { Compliant } \\
(\mathbf{n = 6 5 )} \\
\text { No (\%) }\end{array}$ & $\begin{array}{l}\text { Non-compliant } \\
(\mathbf{n = 3 5 )} \\
\text { No(\%) }\end{array}$ & $X^{2}$ \\
\hline $\begin{array}{l}\text { Took something else for high blood pressure } \\
\text { apart from prescription medication }\end{array}$ & $42(64.6)$ & $33(94.3)$ & $10.681^{* * *}$ \\
\hline 1. Used home remedies for hypertension & $24(36.9)$ & $15(42.9)$ & .337 \\
\hline 2. Faith healing (prayer, tea, holy water, etc) & $26(40.0)$ & $14(40.0)$ & $.000)$ \\
\hline 3. Traditional healing (herbs) & $14(21.5)$ & $12(34.3)$ & 1.921 \\
\hline 4. Over-the-counter drugs & $14(21.5)$ & $7(20.0)$ & .032 \\
\hline$* * * p<.001, * * p<.01,{ }^{*} p<.05$ & & & \\
\hline
\end{tabular}


Table 2: Frequency (and in percent) of agreed responses (as opposed to 'don't know' and 'disagree') on curability of hypertensives by different healing agents

\begin{tabular}{|l|c|l|l|}
\hline X can cure hypertension & $\begin{array}{l}\text { Compliant } \\
(\mathbf{n = 6 5 )} \\
\text { No(\%) }\end{array}$ & $\begin{array}{l}\text { Non-compliant } \\
(\mathbf{n = 3 5 )} \\
\text { No(\%) }\end{array}$ & $X^{2}$ \\
\hline 1. Traditional healer & $1(1.6)$ & $4(13.3)$ & $6.371^{*}$ \\
\hline 2. Faith healer & $4(7.1)$ & $9(26.5)$ & $7.640^{*}$ \\
\hline 3. Modern doctors & $36(55.5)$ & $16(45.7)$ & 2.264 \\
\hline
\end{tabular}

${ }^{* * *} p<.001,{ }^{* *} p<.01,{ }^{*} p<.05$

tion, especially those who had been non-compliant with prescription medication. Most popular were the use of home remedies and faith healing, followed by traditional healing and over-the-counter drugs.

Table 2 indicates the perception of the patients about the curability of hypertension by different healing agents.

Modern doctors were clearly perceived to be superior to traditional and faith healing in "curing" or controlling hypertension. Again, the non-compliant patients believed more in faith and traditional healing than the compliant patients.

Generally, most patients (83) believed that their hypertension is incurable, seven felt it could be cured soon with medication and ten indicated that they would not know how long the sickness will last.

The names used by patients for their hypertension problem were in descending order of frequency: madi a magolo (litt. ,too much blood“) (67), high blood (63), high blood pressure (13), ngope (nose bleeding for a long time) (11), mokola (nose bleeding when in a hot area) (5), and hypertension (3). Madi a magolo is when the person has too much blood wondering in the body causing dizziness and headache. High blood is when blood is too hot and goes up boiling to the head so that you sweat a lotand feel dizzy. Ngope and mokola is when there is too much blood in the body and one bleeds through the nose.

Almost all patients (96) believed that they can tell when their blood pressure is up. The signs for the high blood pressure were perceived to be in descending order of importance: headache (46), dizziness (17), heart palpitations (11), sweating and feeling hot (6) and others (16). About half (51) felt that they could notice changes of blood pressure (51), which were interpreted as follows: feeling well (24), headache or hotness (7), sweating (5), blurred vision (4), and other like tense blood vessels (4).

Table 3 indicates the causative beliefs about hypertension. The three major causes for hypertension as perceived from the Problem Portrait Technique were mental stress, salty and fatty food, whereas the three least important causes were other (old age, menopause, contraception), supernatural and lack of physical exercise.

Case vignette examples for some of the different causative concepts are as follows:

(Mental stress):

„My husband run away and I was supposed to look after our children alone."

„Lost my two children in a car accident. "

„Losing my job because I had swollen legs. “

(Diet):

"I have been eating unhealthy food and gained alot of weight."

„I went to Gauteng to stay with my children and I was eating all sorts of food some of which I did not know. " (Heredity):

„My mother and grandmother had it, so I was bound to have it. "

(Smoking, drinking):

„I have been smoking and drinking for a long time, so now I think that is causing me trouble."

(Physical stress).

"I have been working in the hot sun."

(Supernatural)

"Punishment from ancestors. “

„It was some sort of punishment from God, he wanted me out of the life of sin."

Table 4 indicates the Health Belief Model regarding hypertension.

Both compliant and non-compliant participants believed that hypertension was a serious disease, fear and social limitations from hypertension were seen as a little less than serious. On an open question, more than half (61) feared stroke most about hypertension, 30 death, and nine nothing. The participants also felt much susceptible to hypertension such as stroke, heart attack, kidney disease and blindness. The compliant group believed significantly stronger than the non-complient group that prescription medication was (1) preventing strokes and others, (2) controlling their high blood pressure, and (3) easing their mind. The non-compliant group perceived significantly higher barriers of prescription medication, especially regarding „forgetting“ and ,side effects" of the medication, than the compliant group. Generally, perceived benefits of prescription medication was higher rated than perceived benefits of faith healing, home remedy and traditional healing, in that order. However, perceived barriers or costs of nonwestern treatments (faith healing, home remedy and traditional healing, in that order) were generally perceived as lower than that of western medication. There were no significant differences regarding perceived benefits and barriers for any of the non-western treatments between compliant and non-compliant patients.

Discriminant analysis showed that the overall percentage of cases correctly classified was $77 \%$. Of the 65 patients of the compliant group, 50 (76.9\%) were predicted correctly, while 5 out of 35 (22.9\%) non-compliant cases were identified well.

Table 5 indicates the self-rated and retrospective assess- 
Table 3: Group means, standard deviations and significance tests of hypertensive causative beliefs from Problem Portrait Technique (PPT) rated from 0 to 10 indicating the importance of the behaviour (10 being most important) as well as frequency of agreed responses (in percent) for the compliant and non-compliant groups

\begin{tabular}{|c|c|c|c|c|c|}
\hline \multirow{3}{*}{$\begin{array}{l}\text { Causative beliefs } \\
\text { 1. Mental stress }\end{array}$} & \multirow{2}{*}{\multicolumn{2}{|c|}{$\begin{array}{l}\text { Compliant }(\mathrm{n}=65) \\
M(\mathrm{SD}) \quad \text { No }(\%)\end{array}$}} & \multirow{2}{*}{\multicolumn{2}{|c|}{$\begin{array}{l}\text { Non-compliant (n=35) } \\
\text { M(SD) } \quad \text { No }(\%)\end{array}$}} & \multirow{3}{*}{$\begin{array}{l}\begin{array}{l}\text { Univariate } \\
\text { F-ratio }\end{array} \\
3.201\end{array}$} \\
\hline & & & & & \\
\hline & $6.4(3.6)$ & $50(76.9)$ & $4.9(4.2)$ & $21(60.0)$ & \\
\hline 2. Salty food & $6.2(2.9)$ & $54(83.1)$ & $4.8(3.9)$ & $22(62.9)$ & 3.911 \\
\hline 3. Fatty food & $3.6(3.4)$ & $37(56.9)$ & $3.3(3.8)$ & $16(45.7)$ & .201 \\
\hline $\begin{array}{l}\text { 4. Unhealthy diet (white mealie meal, } \\
\text { sugar, modern food, ) }\end{array}$ & $2.2(3.5)$ & $20(30.8)$ & $2.1(3.1)$ & $12(34.3)$ & .051 \\
\hline 5. Being overweight & $1.3(2.9)$ & $11(16.9)$ & $2.6(4.0)$ & $11(31.4)$ & 3.654 \\
\hline 6. Heredity & $2.2(3.7)$ & $17(26.2)$ & $1.5(3.4)$ & $6(17.1)$ & .803 \\
\hline 7. Smoking & $1.2(2.5)$ & $14(21.5)$ & $1.9(3.3)$ & $9(25.7)$ & 1.422 \\
\hline 8. Drinking alcohol & $1.3(2.6)$ & $14(21.5)$ & $1.7(3.0)$ & $9(25.7)$ & .651 \\
\hline 9. Lack of exercise & $1.5(3.2)$ & $13(20.0)$ & $0.6(2.1)$ & $3(8.6)$ & 2.257 \\
\hline 10. Physical stress & $1.0(2.4)$ & $9(13.8)$ & $1.5(3.0)$ & $7(20.0)$ & .912 \\
\hline 11. Supernatural\# & $0.1(1.2)$ & $1(1.5)$ & $1.2(3.1)$ & $5(14.3)$ & $6.625^{*}$ \\
\hline $\begin{array}{l}\text { 12. Other (old age, menopause, } \\
\text { contraceptives) }\end{array}$ & $0.9(2.4)$ & $8(12.3)$ & $0.5(2.0)$ & $2(5.7)$ & .637 \\
\hline
\end{tabular}

${ }^{* * *} p<.001,{ }^{* *} p<.01,{ }^{*} p<.05$; \#=ancestors, sekgalaka, God

ment of the quality of the practitioner-patient relationship.

Most items of the satisfaction questionnaire with health care professionals were positively rated (11), 6 low and 3 medium. Examples for high ratings were „I think all the health problems we have discussed are important." and „My health care provider is very careful to check everything when examining me.", and examples for low ratings were ,My health care provider misses important information which I give him/her." and „I have health problems which should have been discussed at the hypertension clinic but were not." The compliant patients felt stronger satisfaction with three items of the scale such as ,the health care provider has explained my medical problems to me" than the non-compliant patients. There was no significant between the two groups for the overall scale.

\section{Discussion}

This study assessed health beliefs and compliance behaviour with prescription medication in at least one year diagnosed hypertensives attending an out-patient hypertension clinic in a rural hospital in the Limpopo Province of
South Africa. From the 100 patients studied $35 \%$ were not compliant with prescription medication. Poor adherence to long term treatment, both lifestyle modifications and pharmacological therapy, has been identified as the major reason for inadequate control of elevated blood pressure (Kitler, 1996:5).

In this study the indigenous names used for hypertension were used interchangeably. Similar results were found among White and West Indian hypertensive patients (Morgan \& Watkins, 1988: 561). However, this was different to what was found among African Americans who often discriminated between "high blood/high blood pressure" and "hypertension". Patients considered "high blood"a "blood disease" wherein excessively "hot", "thick", or "rich" blood progressively "rises in the body", whereas "high-pertension" was considered as a "disease of the nerves" (Heurtin-Roberts \& Reisin, 1992: 288).

Medical authorities assert that hypertension is asymptomatic, but the respondents thought in this study otherwise. When asked, "Do you think you can tell when your blood pressure is up?" almost all (91\%) of the participants identified symptoms for detecting elevated pressure. Meyer et al. (1985: 121f.) found that $71 \%$ of the newly treated group 
Table 4: Means and standard deviations of study variables of the Health Belief Model ( $1=$ strongly agree/very likely to $5=$ disstrongly agree/very unlikely)

\begin{tabular}{|c|c|c|c|}
\hline Perception variables & $\begin{array}{l}\text { Compliant } \\
(\mathrm{n}=65) \mathrm{M}(\mathrm{SD})\end{array}$ & $\begin{array}{l}\text { Non-compliant } \\
(\mathrm{n}=35) \mathrm{M} \text { (SD) }\end{array}$ & Univariate F-ratio \\
\hline Severity & $2.16(.61)$ & $2.00(.56)$ & 1.691 \\
\hline $\begin{array}{l}\text { Seriousness } \\
\text { Fear } \\
\text { Limitations }\end{array}$ & $\begin{array}{l}1.65(.74) \\
2.20(.71) \\
2.38(1.03)\end{array}$ & $\begin{array}{l}1.40(.50) \\
2.06(.68) \\
2.29(1.18)\end{array}$ & $\begin{array}{l}3.123 \\
.942 \\
.190\end{array}$ \\
\hline Susceptibility & $2.52(.88)$ & $2.20(.69)$ & 3.477 \\
\hline $\begin{array}{l}\text { Perceived benefits of antihypertensive } \\
\text { medication }\end{array}$ & $2.03(.24)$ & $2.34(.72)$ & $9.949^{* *}$ \\
\hline $\begin{array}{l}\text { Blood pressure } \\
\text { Prevent strokes } \\
\text { Ease one's mind }\end{array}$ & $\begin{array}{l}2.00(.18) \\
2.05(.45) \\
2.02(.41)\end{array}$ & $\begin{array}{l}2.26(.85) \\
2.51(.95) \\
2.31(.83)\end{array}$ & $\begin{array}{l}5.524^{*} \\
11.205^{* * *} \\
5.769^{*}\end{array}$ \\
\hline $\begin{array}{l}\text { Barriers/perceived costs of } \\
\text { antihypertensive medication }\end{array}$ & $4.91(.70)$ & $3.05(.45)$ & $33.494 * * *$ \\
\hline $\begin{array}{l}\text { Financial } \\
\text { Forgetting } \\
\text { Refills } \\
\text { Side effects }\end{array}$ & $\begin{array}{l}2.95(1.33) \\
4.11(.75) \\
3.86(.77) \\
3.69(.90)\end{array}$ & $\begin{array}{l}2.71(1.25) \\
2.63(1.21) \\
3.94(.54) \\
2.91(1.25)\end{array}$ & $\begin{array}{l}.771 \\
56.443^{* * *} \\
.309 \\
12.903^{* * *}\end{array}$ \\
\hline Perceived benefits of traditional healing & $3.06(.86)$ & $2.87(1.00)$ & .965 \\
\hline Perceived barriers/costs of traditional healing & $2.73(.36)$ & $2.73(.36)$ & .119 \\
\hline Perceived benefits of faith healing & $2.71(.78)$ & $2.61(.81)$ & .373 \\
\hline Perceived barriers/costs of faith healing & $2.95(.42)$ & $3.05(.37)$ & 1.297 \\
\hline Perceived benefits of home remedy & $2.83(.72)$ & $2.68(.56)$ & 1.072 \\
\hline Perceived barriers/costs of home remedy & $2.85(.44)$ & $2.76(.44)$ & .341 \\
\hline
\end{tabular}

for hypertension, $92 \%$ of the continuing treatment group, and $94 \%$ of the re-entry group identified symptoms for detecting elevated pressure. Signs for high blood pressure were perceived to be: headache, dizziness, heart palpitations, pain, sweating, breathlessness and others. Morgan and Watkins (1988: 568) found among White and West Indian hypertensive patients that symptoms perceived as indicating a rise in blood pressure were in descending order of importance: pains or sensations in head, weakness/ tiredness, eye problems, dizziness, and feeling hot.

Non-compliant behaviour was associated with the use of taking something else for high blood pressure apart from prescription medication, the belief of curability of hypertension by traditional and faith healers, perceived benefits of antihypertensive medication, perceived barriers of antihypertensive medication, and some items of the quality of the practitioner-patient relationship such as medical expla- nation was not given. Especially the non-compliant patients believed that their hypertension was curable as opposed to incurable in the compliant patients. Lack of chronicity limits the importance of following a prescribed treatment (Schoenberg, 1997: 174). Only a few items on the quality of the practitioner-patient relationship (general satisfaction, understandable language, expressibility, not explaining medical problems) were associated with compliance behaviour. Esunge (1991: 292) found among rural hypertensive clinic attenders in Cameroon that open discussion with medical staff, use of a common dialect, and politeness of medical staff influenced patient compliance.

Interestingly, however, was that causal beliefs, perceived severity and susceptibility of hypertension, and perceived benefits of alternative healing agents were not associated with compliance behaviour.

Similar to another study in South Africa there was a pre- 
Table 5: Means, standard deviations and t- test for the quality of practitioner-patient relationship of the compliant and non-compliant group (scored from $1=$ strongly agree to $5=$ strongly disagree)

\begin{tabular}{|c|c|c|c|}
\hline $\begin{array}{l}\text { Quality of practitioner-patient relationship: } \\
\text { (a) My health care provider ... }\end{array}$ & $\begin{array}{l}\text { Compliant } \\
(\mathrm{n}=65) \mathrm{M}(\mathrm{SD})\end{array}$ & $\begin{array}{l}\text { Non-compliant } \\
(\mathbf{n}=35) \mathrm{M}(\mathrm{SD})\end{array}$ & $t$ \\
\hline 1....is very careful to check everything when examining me & $2.09(.52)$ & $2.23(.63)$ & 1.110 \\
\hline 2. ...seems to be very competent and well trained & $2.06(.43)$ & $2.26(.77)$ & 1.574 \\
\hline 3....misses important information which I give him/her & $4.03(.39)$ & $3.94(.69)$ & 1.065 \\
\hline 4. ...is not as thorough as she/he should have been & $3.83(.78)$ & $3.82(.90)$ & .337 \\
\hline $\begin{array}{l}\text { 5. The medical problems I have had in the past have been } \\
\text { ignored during my visits }\end{array}$ & $3.66(1.02)$ & $3.65(.85)$ & .163 \\
\hline $\begin{array}{l}\text { 6. There are many things about medical care I have received } \\
\text { that could be better }\end{array}$ & $2.85(1.05)$ & $3.18(1.00)$ & -1.369 \\
\hline $\begin{array}{l}\text { 7. I think my health care providers have a good understanding } \\
\text { of my health history }\end{array}$ & $2.26(.69)$ & $2.29(.76)$ & .530 \\
\hline $\begin{array}{l}8.1 \text { have a great deal of confidence in the health carers who } \\
\text { have treated me }\end{array}$ & $2.20(.69)$ & $2.47(.90)$ & 1.930 \\
\hline 9. 1 am very satisfied with the medical care I have received & $2.14(.68)$ & $2.59(1.05)$ & $2.679 * *$ \\
\hline $\begin{array}{l}10 . . . \text { has really seemed to care about me and my health } \\
\text { problems }\end{array}$ & $2.09(.55)$ & $2.21(.69)$ & 1.078 \\
\hline 11....has explained things in words I could understand & $2.05(.62)$ & $2.44(1.02)$ & $2.342 *$ \\
\hline 12...let me tell him/her everything I thought was important & $2.34(.85)$ & $2.44(1.02)$ & $2.221^{*}$ \\
\hline $\begin{array}{l}\text { 13. I would not feel comfortable asking my health carer } \\
\text { questions }\end{array}$ & $3.60(1.04)$ & $2.79(1.07)$ & 1.398 \\
\hline 14....has not explained my medical problems to me & $4.00(.79)$ & $3.26(1.14)$ & $3.007 * *$ \\
\hline $\begin{array}{l}\text { 15....has had a complete understanding of the things that are } \\
\text { wrong with me }\end{array}$ & $2.46(.75)$ & $3.47(.99)$ & .413 \\
\hline $\begin{array}{l}16 . \text {...has known what I thought were my most important } \\
\text { health problems }\end{array}$ & $2.34(.78)$ & $2.53(.83)$ & 1.726 \\
\hline $\begin{array}{l}\text { 17. ...has known what health problems I have wanted to } \\
\text { talk about }\end{array}$ & $2.28(.78)$ & $2.56(.96)$ & 1.323 \\
\hline $\begin{array}{l}\text { 18. I think all the health problems we have discussed are } \\
\text { important }\end{array}$ & $1.92(.27)$ & $2.09(.57)$ & 1.558 \\
\hline $\begin{array}{l}\text { 19....has not had a complete understanding of the things } \\
\text { that are wrong with me }\end{array}$ & $3.94(.53)$ & $3.71(.80)$ & 1.904 \\
\hline $\begin{array}{l}\text { 20. I have health problems which should have been discussed } \\
\text { at the hypertension clinic but were not }\end{array}$ & $3.98(.74)$ & $4.00(.55)$ & -.306 \\
\hline Total & $2.22(.07)$ & $2.39(.06)$ & 1.640 \\
\hline
\end{tabular}


ponderance of women in this sample (67\%). Lunt, Edwards, Steyn, Lombard and Fehrsen (1998: 544) found that among 1098 hypertensive clinic attenders in a Cape Town community health centre that $81.7 \%$ were female. The low proportion of male hypertensives attending the teaching hospital suggests that the accessibilty or acceptability of this group is poor.

Mental and environmental stress was mentioned frequently by the patients as causative beliefs in this sample, which was similar to what was found among White and West Indian hypertensives (Morgan \& Watkins, 1988: 561). Little was mentioned about supernatural causes of hypertension. However, Schoenberg (1997: 179) found among African-American rural elders with hypertension that the most frequently mentioned means of controlling high blood pressure included avoiding and eating certain foods, losing weight, praying, reading the Bible, taking home remedies, and exercising.

Discriminant analysis showed that regarding different parametres measured that the compliant behaviour was more predictable than the non-compliant behaviour. For example, regarding health beliefs $76.9 \%$ of the compliant but only $22.9 \%$ of the non-compliant group were predicted correctly. This seems to indicate that non-compliant behaviour is complex and cannot be reduced or isolated to specific factors as compared to compliance behaviour.

Perceived barriers to antihypertensive medication was significantly higher among the non-compliant than the compliant patients, in particular regarding forgetting, side effects and costs of antihypertensive medication. Esunge (1991: 293) also found among rural hypertensive clinic attenders in Cameroon that free medication and transportation positively influenced patient compliance. In this study experiencing side effects were associated with non-compliance with antihypertensive medication. It was found from the analysis of physician-patient interactions with hypertensives that only a few doctors informed the patient about possible side effects of the prescribed medication (Peltzer, Mekwa, Khoza, Lekhuleni, Alberts, \& Sethosa, 2002: 171). Lisper, Isacson, Sjöden and Bingefors (1997: 147) found from Swedish hypertensive patients that they expressed a desire to receive information at the beginning of the pharmaceutical treatment, especially concerning possible side-effects.

Study limitations included that this was a cross sectional study representing one point in time not reflecting possible changes in individual perceptions, beliefs and behaviours over time. Another important limitation of this study was that compliance with prescription medication was obtained by self-reports. However, these self-reports were cross checked by also investigating the hospital files, since patients had to space appointments in between their clinic attendance with the hospital. Moreover, the results of selfreported medication use in other studies indicate that selfreports are good estimates of actual medication taking practices (Brown \& Segal, 1996: 914). Furthermore, the hospital sample studied here was not able to include those hypertensive cases who had dropped out from treatment previously and have gone elsewhere for follow-up treatment, which means that some of the truely non-compliant cases could not be included. A further study is suggested to spe- cifically investigate health beliefs among those hypertensive cases who drop out from treatment completely.

\section{Conclusion}

As a conclusion, factors that improve compliance include culturally sensitive patient education and attitude about the disease undergoing treatment (Elliot, 1994: 271). More research is needed to improve our understanding of cultural belief's in managing chronic illnesses. This study demonstrated in line with a study among African American and White American hypertensives (Brown \& Segal, 1996: 903) that alternative healing agents such as home remedies, faith healing and traditional healing play an important role in the management of hypertension in terms of taking alternative healing modes only or concurrently with antihypetensive medication. The study findings further support that the suggestion that patient belief systems should be considered when developing interventions and when monitoring patient outcomes. The implication is that health and medical care providers can help to improve compliance with prescribed regimens by helping patients incorporate the regimens into their daily routines or by changing the medication so that side effects are minimized. In addition, providers should actively and nonjudgementally elicit patient beliefs about the use of home remedies, faith or traditional healing so that they can be aware of the potential for concurrent use with prescriptive medication (ibid.).

\section{Acknowledgement}

Funding was provided by the Research Office of the University of the North.

\section{References}

BECKER, M 1979: Patient perceptions and compliance studies of Health Belief Model. In: R.B. Haynes, D.W. Taylor \& D.L. Sacket (Eds.) Compliance in health care (pp. 48-62). Baltimore: John Hopkins University Press.

BLUMHAGEN, D 1982: The meaning of hypertension. In: N.J. Chrisman \& T.W. Maretzki (eds.) Clinically applied anthropology (pp. 297-323). Dordrecht: Kluwer.

BROWN, CM \& SEGAL, R 1996: The effects of health and treatment perceptions on the use of prescribed medication and home remedies among African American and White American hypertensives. Social Science \& Medicine. 43: 903-917.

DEPARTMENT OF HEALTH 1998: South Africa demographic and health survey. Pretoria: Author.

ELLIOT, WJ 1994: Compliance strategies. Current Opinion in Nephrologv and Hypertension. 3: 271-278.

ESUNGE, PM 1991: Patient compliance and the evaluation of drug trials for hypertension in rural Africa. Ethnicity and Disease. 1: 292-294. 
GRANT, M 1993: Women's health beliefs regarding hypertension. West Indian Medical Journal. 42: 158-160.

HAYNES, RB; MCKIBBON, KA; KANANI, R; BROUWERS, MC; \& OLIVER, T 1998: Interventions to assist patients to follow prescriptions for medications. In: L. Bero, R. Grilli, J. Grimshaw. \& A. Oxman (Eds.) Collaboration of effective professional practice module of the Cochrane Database of Systematic Reviews /updated 01 December 1997|. Available in The Cochrane Library.

HEURTIN-ROBERTS,S \& REISIN, E 1992: The relation of culturally influenced lay models of hypertension to compliance with treatment. American Journal of Hypertension. 5: 787-792.

KITLER, ME 1996: The changing face of hypertension and antihypertensive agents. Drugs Aging. 8: 5-11.

LISPER, L; ISACSON, D; SJÖIEN,P-O \& BINGEFORS, K 1997: Medicated hypertensive patients" views and experience of information and communication concerning antihypertensive drugs. Patient Education and Counseling. 32: 147-155.

LUNT, DWR; EDWARDS, PR, STEYN, K; LOMBARD, CJ \& FEHRSEN, GS 1998: Hypertension care at a Cape Town community health centre. South African Medical Journal. 88: 544-548.

MACLACHLAN, M 1997: Culture and health. Chichester: John Wiley.

MEYER, D; LEVENTHAL, H \& GUTMANN, M 1985:Common-sense models of illness: the example of hypertension. Health Psychology. 4: 115-135.

MORGAN, M \& WATKINS, CJ 1988: Managing hypertension: beliefs and responses to medication among cultural groups. Sociology of Health \& Illness. 10: 561-578.

MORREL, RW; PARK, DC; KIDDER, DP \& MARTIN, M 1997: Adherence to antihypertensive medications across the life span. Gerontologist. 37: 609-619.

NYAZEMA, NZ 1984: Towards better patient drug compliance and comprehension: a challenge to medical and pharmaceutical services in Zimbabwe. Social Science \& Medicine.

$18: 551-554$.

PELTZER, K; MEKWA,J;KHOZA,LB; LEKHULENL,ME; ALBERTS, M \& SETHOSA, E 2002: Factors at follow-up associated with prescribed medication for hypertensive patients from a rural teaching hospital in South Africa. Journal of Psvchologv in Africa. 12(2): 161-179.

SCHOENBERG, NE 1997: A convergence of health beliefs: an "ethnography of adherence" of African-American rural elders with hypertension. Human Organization. 56: 174181 .
STATISTICS SOUTH AFRICA 1998: Population census, South Africa, 1996. Pretoria: Statistics South Africa.

WHO 1993: Improving adverence behaviour with treatment regimens. Geneva: author. 